\title{
Research on the Path of Constructing the Students' Psychological Consultative Education Platform of Private College by Using WeChat
}

\author{
Mingxia Zhang ${ }^{1,}$, Jing Fan $^{2, b}$ \\ ${ }^{1}$ Xi'an Peihua College, Xi'an, Shaanxi, China, 710077 \\ ${ }^{a}$ email,
}

Keywords: Psychological Consultative Education Platform, Private College, WeChat

\begin{abstract}
Private college psychological counseling has become a certain scale after experienced the rise of reform and opening up and decades of development, it has made great achievements. Throughout its development, we see the results, but also see the shortcomings. With the progress of society and the ever-changing network technology, this work should also keep up with the pace of the times. The emergence and widespread use of "WeChat" had great impact on college students in the study and life. The existing theory and technology show that only the full consideration of the student's conduct is good, the style of action is emotional and interpersonal relationship and the initial attitude and many other factors, can we better use the "WeChat" to build college students psychological counseling education platform. This article is intended to explore the innovation platform of psychological counseling platform - "WeChat" psychological counseling.
\end{abstract}

\section{Introduction}

Although the private colleges and universities have a great gap with the public colleges and universities, but their students need to be resolved in the psychological counseling problems less than the public colleges and universities. In the system of psychological counseling in colleges and universities, psychological counselors are the core forces and their ability to grow in the psychological health of college students is of great significance.

Psychological counseling, including two aspects, one is mental illness, physical and mental illness, all kinds of psychological disorders; the second is to enable visitors to better understand themselves and society, enhance social adaptability, give full play to potential and achieve comprehensive development. Although they are two different areas of work, but the work of the two goals are consistent, that is, to create a perfect personality of college students, so that it has excellent quality. In solving the psychological problems, if we can build a reasonable value of the consultation system, cultivate the correct three views, is conducive to the solution of psychological problems. Because many of the psychological problems of college students directly attributed to the desalination of faith, value orientation distorted. At the same time, strengthening the psychological quality education of college students is an important content of ideological and political work in contemporary colleges and universities. In the socialist market economy, the students are facing challenges and opportunities are unprecedented, if there is no strong setbacks, I am afraid cannot adapt to this society. At present, data show that in the near graduation time, college students are prone to crisis events in the high period of time cannot find a job or work to find the ideal is often an incentive.

In recent years, the continuous development of psychological counseling in colleges and universities, psychological counseling positions on the staff demand and work requirements increased year by year. China's qualification requirements for college counselors, mainly with the qualifications of teachers eligible for correspondence, also need a master's degree, psychological background. This requirement is compared with the American universities, there is a certain gap, especially the gap between professional ability, our university psychological counselor's work experience and effect did not make the request or less. And the United States colleges and universities on the staff of the post have a specific standardized and professional vocational training, third-party supervision and supervision to make it faster and more stable to be improved. 
For the construction of college psychological counseling an effective model, has been launched in most colleges and universities. Psychological counseling has become an organic part of quality education in colleges and universities. In colleges and universities should pay attention to the individual consultation and universal education combined. With the development of society, the network goes deep into the life and psychology of each college student. The social environment has changed. If the way of psychological counseling does not change accordingly, it is difficult to keep up with the demand. How to take preventive measures, just rely on the traditional individual consultation cannot solve the problem, because when the individual came to the consultation, the problem is often not a good solution. Extensive education can play a certain preventive role. How to effectively use the network to expand a wide range of education or individual guidance, at this stage is very practical significance. Therefore, we should try to do the following: First, the spring rain, moisten things silent, timely and comprehensive early prevention of students to play; the second is to improve the ability of college students to self-psychological debugging so that the initial problems appear in time to solve; Effectively alleviate the current shortage of college consultants contradictions. The "public letter" platform is an effective tool for universal education, which will be described in detail in the third part of this article.

Private college students have a strong social sensitivity, their theoretical level of knowledge is less than the public school students, but their ability to insight into the community is not bad at all. How to make them better adapt to the community, private college counselors, ideological and political teachers are long way to go. Private colleges and universities because of the particularity of their school, in the proportion of staff without public schools so superior, so you can try, part-time psychological counselor combination of the path, while improving the psychological counseling self-development mechanism. This aspect is mainly to do the following: First, increase publicity efforts. Second, give full play to service functions. The third is to establish the necessary incentives. Fourth, vigorously improve the quality of consultants.

\section{The Development and Effect of Network Psychological Counseling in Colleges and Universities}

Because of the definition of network counseling is not unique, this paper is based on the definition of American National Association of Registered Counselors, that the psychological counseling and psychological counselor and counselor with e-mail, chat tools, network video and other equipment, Synchronous / real-time or asynchronous / non-real-time interaction. Chatting tools can solve the problem of time, while this way can solve one-on-one, but also can solve one-on, in the understanding of the emotional and the degree of personal impact, this approach and interview no significant difference, but its drawback is that there is no interview so close, not too easy to reveal themselves. Video consultation is the closest to the face of psychological counseling situation. At present, the domestic university video consultation is also limited by the various conditions and cannot be universal. It is not difficult to see that the network of psychological counseling with anonymity, convenience, text and voice, image communication and so on. Relying on the theoretical and technical aspects of the following points: First, narrative therapy, the second is the focus of the solution therapy and the third is cognitive behavior therapy. Whichever method is used, the techniques include: emotional deepening, relationship promotion, and text presentation. In the psychological counseling with the network, we also take into account their corresponding ethical issues, such as informed consent, confidentiality and early warning, to avoid injury. We can foresee that the network of psychological counseling will be with the rapid development of electronic technology and become more convenient and adventurous, whether through the appropriate development of psychological counseling network to achieve the purpose of change and growth is still being explored.

With the further popularization of the network, network counseling developed rapidly. 2004 "China Psychological Hotline" statistics of the site to visit more than 1 million people, the current site visits have more than 50 million. It can be said that the development of network counseling is very rapid. China's psychological counseling industry started late, coupled with the concept of the 
problem, many people have psychological problems do not seek help. But with the accelerated pace of life and people's increasing pressure, more and more people have the needs of psychological counseling. Network interaction, virtual, equal, multimedia, real-time can win more and more people rely on it. The above description of the network psychological counseling for the popularization of psychological counseling provides the conditions. At the same time we can also see that the network of psychological counseling to help the psychological counseling theory, technology and counseling model for innovation. For example, the emergence of postmodern psychological counseling theory is a good proof. Moreover, psychological counseling theory and technology from single to integration has emerged a clear trend. Another advantage of network counseling is that it helps to share resources and provide large data. China's psychological counselors are quite scarce, from the number of view, far less than the United States and other developed countries. How to effectively use resources, the network is undoubtedly a better choice. The immediacy of the Internet, the global cooperation for the sharing of resources provided the possibility.

Of course, the network of psychological counseling for the development of psychological counseling has brought challenges. The first is the challenge of resource management, the use of psychological software and the operation of the psychological quality of different professional staff, will make the consultation results very different. Followed by the challenges of traditional consulting technology, such as software development, identity and other issues will have an impact on the application. Again is the challenge of the consultants, the use of the network for psychological counseling, consultants are keen observation, analysis and debate is profound, whether the sense of responsibility is an important factor affecting the results of the consultation. Finally, the challenge of case tracking, network counseling are difficult to track the case, because most of the behavior of visitors with tentative and random.

Different age and the use of the network will also affect the effectiveness of network consulting. The results of the questionnaire also show whether the conduct is good, whether the style of action and interpersonal relationship and the initial attitude will affect the network of psychological counseling results.

\section{The Application of Campus "WeChat" Platform in Psychological Counseling}

The data show that "WeChat" as a college student favorite mobile media, has become an important channel for college students to communicate and communicate themselves. The "WeChat" has the important influence on daily behavior of college students, ideological and moral, learning atmosphere and so on by. It has brought convenience for college students, psychological counseling for colleges and universities to provide a new platform. In the opportunity to bring the same time, inevitably bring challenges. To explore how to use the "WeChat" to start a new form of psychological counseling for college students, new ways to reflect the concept of advancing with the times.

"WeChat" is Tencent launched instant messaging service applications, just a few years time there have been hundreds of millions of users on the scale of traffic. The software supports multi-person mobile phone for free voice messages, video, pictures and text communication. The reason why college students become the software's great fans and their daring can try new things inseparable. In the students circulating "WeChat" terrible and ferocious remarks, and "WeChat" communication mode and communication of new and energy is not unrelated. "WeChat" with openness and popularity makes it possible for college counseling work has the possibility of life. Students in the school time is their "three views" is being developed during the identification of right and wrong, self-control ability is not enough, this period of frequent psychological problems is an urgent need to be effectively resolved in some way. "WeChat" can strengthen the students and students in the school, the links between friends, but also can play to promote the close contact between teachers and students. "WeChat" to meet the emotional needs of college students, through the "sun" mood, "sun" in kind, "sun" landscape, they are at any time with the outside world; friends circle expression and talk voices are the only choice, WeChat "to college students to provide a lot of interpersonal 
convenience. How to play a good "WeChat" role is very important. "WeChat" to help break the psychological counselors and respondents in the reality of the gap between the equal identity of the dialogue, the harmony of both sides of the atmosphere, but also improve the efficiency of the consultation. "WeChat" for the relationship was once in a dusty state of the teachers and students to provide icebreaker. In the current most of the psychological counseling work by the ideological and political teachers as the case, the icebreaker produced a revolutionary effect. It allows the communication between teachers and students continue to the extracurricular. Students can understand the teacher through a circle of friends and teachers can also understand the students. "WeChat" interactive and real-time, so that the teacher of each student's dynamic real-time understanding, it cannot be said to be a "broken empty." And the previous network application is different from the "WeChat" through a friend authentication, you can confirm the true identity of the object and before the identity of the network because of the problem, many psychological counseling objects are holding tentative and random psychology, WeChat "to solve this problem. As the "WeChat" circle of friends can understand a person's usual life dynamics, including the person's mood, hobbies and other aspects, is conducive to psychological counselors access to all aspects of psychological counseling information. The ancients cloud "people to group points", from a person to friends to see this person is also an effective and simple way. Consultants can find some of the information they need in the consultation object cannot be said to be an effective way. In the campus of the "WeChat" public platform can be popularization of psychological counseling education, often made some psychological aspects of the article, some popular science students during the school prone to psychological problems and coping strategies, effective prevention is feasible. At the same time, by participating in the discussion of the students in the question to answer the situation, find out the students tend to psychological problems. In short, "WeChat" for college psychological counseling has its advantages and even many advantages.

Of course, anything is a two-sided, "WeChat" is no exception, in the effective application of "WeChat" platform for psychological counseling at the same time and we also face many challenges. College students' management departments should develop appropriate quality, strengthen supervision, the purpose is to ease and manage the negative factors, and actively promote health factors. The specific approach is as follows: First, the establishment of college students to use "WeChat" management information exchange and feedback development. Second, establish the monitoring system of college students to use "WeChat". The third is to cope with the cultural characteristics of openness.

"WeChat" can be used for psychological counseling is an effective way, this article looks forward to more scholars and experts to carry out research on related issues, so that "WeChat" really play a better function in the work.

\section{Acknowledgements}

Fund Project: Research on path of constructing private college students' psychological counseling and education platform using "WeChat" (Xi'an Peihua College 2016 college students' ideological and political education topics No.PHSZ20161104)

\section{References}

[1] Zhu Chunlan, Li Zhengyun, Gu Haigen. Psychological counseling in colleges and universities: status quo, problems and development [J] Shanghai Youth, 2012, 04, 25-26

[2] Li Zhongyan. Talking about the development of psychological counseling in colleges and universities [J] Education Exploration, 2003.07, 144-145

[3] Li Chengqi. Network psychological counseling research summary [J] China Special Education, 2007.05, 144-145

[4] Peng Yang. Network psychological counseling: psychological counseling and development 
opportunities and challenges [J] Journal of Higher Education Research, 2006.09, 21-23

[5] Hong Yuhua. Network psychological counseling - a new way of psychological counseling in colleges and universities [J] Science and Technology Information, 2008.09, 74-76 